The most fundamental contribution to the new geology is the dynamic scheme as outlined by James Hutton, the so-called " geostrophic cycle" cycle of changes in the earth in which the rocks exposed at the surface through the process of weathering, denudation and transportation are deposited, consolidated and eventually metamorphosed and even magmatised and again brought to the surface of the earth. The geostrophic cycle, which can be diagramatically represented by a circle with directional arrows separating processes from products, provides us with the logical core of the science of geology, in which the "order of nature" is reflected and transmuted by the mind into an "order of concepts". This provides a scheme which explains the relation of the science of geology to its subject matter. Another scheme, which explains the internal structure of the science of geology and the relation between geology and other sciences, is provided by the "geological octahedron ". This is a model of an octahedron with sides placed horizontally (the lower side is left open and the octahedron is balanced on a needle, the point of which is placed in the middle of the lower surface of the upper face). The upper triangle of the octahedron represents the science of geology, the three aspects of which-material, disposition, process-are placed at its corners. The lower triangle, with its three corners occupied by chemistry, physics and biology, represents the fundamental sciences of nature upon which geology rests. Looking at such a logico-mathematical model one can easily discern the definition of geology as a soience which investigates the MATERIAL constituents of the earth, their DISPOSITION and the PROCESSES involved in their formation and distribution.

\title{
History of Science in Education
}

ABSTRACTS of Papers read at the Discussion held on 27th February, 1950, in the Lecture Theatre of the Royal Institution of Great Britain.

By PROFESSOR H. DINGLE

Professor of the History and Philosophy of Science, University of London

Professor Dingle, in opening the discussion, emphasised the difference between the historical development of science and its development as a logical system from fundamental axioms or postulates. Of necessity the latter must take pride of place in the training of students for immediate practical work, but the opportunity should not be lost of pointing out that what guided the pioneers in making fresh advances was very rarely what appeared later to be the logical requirements of the situation, but was frequently the impact of considerations once important but now largely forgotten. An example was found in the theory of heat. It is not uncommon for text-books to present Rumford's experiments on the boring of cannon as having given the death-blow to the fluid theory, because we can now see clearly that those experiments are far better explicable in terms of a kinetic theory. In fact, however, neither Rumford himself nor his contemporaries drew this conclusion and the fluid theory lasted for another half-century until it was overthrown by the new doctrine of energy.

Professor Dingle then gave an outline of the courses in the History and Philosophy of Science at University College, London. These were postgraduate courses leading to M.Sc. and Higher Degrees, and were open to students who had graduated in a scientific subject. Beginning in a comparatively small way in 1925, the Department now had a staff of six full-time teachers, as well as assistance from visiting Lecturers, and an enrolment of about 50 students. Its appeal extended to the most distant parts of the world and clearly indicated 
the need for such courses to be established wherever the library facilities were such as to make work of a sufficiently high standard possible. A very satisfactory feature of the courses was the high proportion of Teachers and Instructors in Training Colleges who attended them, for the influence of teaching in the history of science was thus extended over a much wider field than that of the students alone. Many of those who attended had taken up the history of science as a life interest and had done valuable original research in it.

\section{By DR. H. F. BOULIND \\ Science Masters' Association}

Dr. Boulind began by saying that his remarks represented solely his own views, and not those of the Science Masters' Association as a body.

History of Science is an important section, an often neglected section, but nevertheless only one section, of the much wider subject of the whole history of mankind. The subject is usually left to the science master, who has not the teaching time available and, in any case, History of Science taught by itself, divorced from its social or any other context, tends to degenerate into a pleasantly soporific collation of anecdotes. It should be taught as part of history ; usually only the historian has the extensive background needed to co-ordinate and correlate all facets of history, including science, into one whole. How can the historian attain the necessary scientific outlook ? Perhaps it will come gradually as more science is taught in schools, but the Universities are ultimately responsible; we may hope that courses on History of Seience will be attended by historians as well as scientists.

The science master is, however, concerned with the historical method as a possible way of presenting science. The historical method has undoubted disadvantages and is in no way a substitute for experimental work, but it is one of the best ways of dealing with theoretical concepts. No boy who has been taught by the historical method should ever confuse science with dogma, should ever misunderstand the nature of scientific truth, or say, "of course we know these theories were wrong; nowadays we know the correct and final explanation ".

Another way of introducing History of Science is in a course on the Philosophy of Science that might be given to both Arts and Science sixth-forms. History enters into this twice over: first in considering examples showing how scientific knowledge has been attained, and second, in tracing the history of scientific method itself. Such a course has a raison d'être; a connecting thread runs through the historical sequence. History of Science is not really a subject in its own right; it must be closely connected with either History or Science.

\section{By K. C. BARNES, Esq.}

\section{Science Masters' Association}

While there are dangers in making history relevant to the present day, it is reasonable that we should wish to bring into education those historical developments that enable us to understand our present world, a world in which the most outstanding feature is the enormous progress in scientific control. History has to be rewritten for every generation, because the experience of each generation becomes itself part of history and inevitably alters the viewpoint. 
A leading historian maintains that what is first necessary is a more complete history of science itself, of scientific thinking. But it is becoming more evident that to understand the development of a scientist's thought we must examine also the whole intellectual climate and even the emotional climate of his time. When this is done, as it has been by Dr. C. E. Raven in his R.I. lecture and by Professor Butterfield and his associates in broadcasts, the result is unusually stimulating ; especially so, in the writer's experience, to boys and girls in Sixth forms.

It is possibly true that the history of science is best written by a historian who also knows science, but the number of such men is exceedingly few and the lack of interest on the part of history students in science is appalling. The root of this evil is in the Sixth Form at school, where pupils, through specialisation, are encouraged to feel that to acquire the dignity of students they must limit their interest and awareness. Higher Certificate history papers encourage an extremely narrow view of history, often ignoring completely the Scientific Revolution of the seventeenth century and implying no recognition of the part that science has played in shaping the modern world.

\section{By MIss F. R. ELWELL}

Association of Women Science Teachers

The study of the History of Science can result in an enrichment of understanding comparable with that resulting from the study of any other humanity ; some acquaintance with scientific trends in the past may contribute towards an appreciation of the significance of science today.

The great majority of people have little background knowledge of science or of history and none at all of the history of science; ninety-nine in every hundred in school today will never reach a University; nine in every ten never get as far as a Sixth Form; three in every four never attend a Grammar School.

In science broadcasts to Secondary Modern Schools-children of from 11 to 15-aspects of the History of Science play an important part. There are biographical broadcasts on Faraday, Davy, Linnaeus, Marie Curie, Newcomen, Trevithick, Leeuwenhoek, Galileo and many other great scientists. We attempt in these broadcasts to make the children aware of the social importance of a piece of scientific work-0tto's invention of a practicable internal combustion engine, for example ; to give them some idea of how a scientist sets about his work-the necessity, for example, of controls illustrated by some of the classic experiments of Spallanzani or Pasteur ; to give a picture of the character of the man himself and the qualities that made him outstanding ; to show him against a background of contemporary characters, events of general historic interest, and the social life of his time. Programmes about such men as Priestley, Lavoisier, Leonardo, Franklin, can have an important function in helping to overcome the artificial segregation of subjects in the school curriculum. The fact that a scientist could also be an artist or a politician or a theologian can provide a starting point for a discussion, at a very simple level, of the inter-relationship of various aspects of life and culture today.

In the field of adult education there are many problems to be considered. Recent experiments on intelligibility have shown limitations of vocabulary not adequately realized by many speakers and writers on scientific topics.

A great deal of care and thought needs to be given to the popular presentation of scientific topics and to basic problems of simple exposition. 


\section{By D. B. TAYLOR, Esq.}

British Broadcasting Corporation

Mr. Taylor gave a short account of the series of Broadcasts on the History of Science which were being given to schools in the autumn and spring terms, 1949-50. These talks were being repeated in the Third Programme and were also recorded by the BBC Transcription Service for re-broadcasting overseas. His remarks could only be very general because the series was still running; when it was finished the School Broadcasting Department and the School Broadcasting Council would be in a position to make a much fuller survey. It was therefore unsuitable to make final pronouncements at that stage. There was, however, reason to believe that the series had aroused considerable interest in schools. Mr. Taylor exhibited a pamphlet produced by the Corporation for distribution to schools ; this gave a general introduction to the series, a list of the speakers, a bibliography of suitable books dealing with the History of Science, short summaries of the talks, and a list of suggested topics for discussion in sixth forms.

\section{By E. M. HUTCHINSON, Esq.}

\section{National Institute of Adult Education}

The problem facing workers in adult education is the admittedly low proportion of classes in the Natural Sciences figuring in class programmes of Tutorial Class Committees, W.E.A. Districts, etc.

The most recent survey of the problem is contained in the report of a Committee established jointly by the National Institute of Adult Education and the British Association for the Advancement of Science.*

The Committee after reviewing earlier surveys paid special attention to the need for recruiting whole and part-time tutors, and stressed the need for full-time organising tutors in the employment of University Extra-Mural Departments who could help in the recruitment of part-time tutors as well as in establishing classes.

Recent research by Dr. Flood of Birmingham raises doubts as to whether the historical approach is a good entry to the study of science by non-specialist adults.

Attention was drawn to Dr. Flood's two contributions to "Adult Education"* in December 1948 and December 1949 entitled "Interests in Popular Science ".

Teachers and others with an interest in Science teaching to adults may not find it easy to find a field of work because very few of the administrative and organising staffs concerned are themselves seized of the importance of this aspect of adult education. Knowledge of this fact may encourage potential tutors to press the claims of their subjects. It is certainly clear that there is a latent demand that occasional tutors have successfully tapped.

* "Science in Adult Education ", 1/-; "Adult Education ", a quarterly review, 10/6 por annum. Both available from the National Institute of AduIt Education, 55, Queen Anne Street, London, W.1. 
By H. E. POOLE, Esq.

-Workers' Educational Association

Although the number of classes in science provided by the Workers' Educational Association is not as large as the importance of the field merits, last year 5.9 per cent. of all classes were concerned with some aspect of science, a proportion which put science sixth in the order of class interest. There is no way of knowing how many of these classes were in the history of science, but evidence collected from classes now in session suggests that the number was very small.

On the whole, adult students require from the subjects they study information which will help them to understand the world around them. In science, therefore, the demand is for classes dealing with current scientific developments, with the rôle of science in the modern world, with the nature and application of atomic energy, for example.

The students concerned are adults, anxious often to clarify their social, political and religious beliefs, and discussion of scientific problems frequently involves their consideration in their social and political and even moral aspects.

This kind of interest should lead one stage further to the history of science, with its data about the past relationships between scientific development, philosophical beliefs, and social and political organisation which may be used as a guide to working out corresponding relationships today.

This is the type of study in which W.E.A. members are keenly interested, but lack of qualified tutors prevents the organisation of the type of course that is required. Such courses make great demands upon the tutors, whether they be primarily historians or scientists, for in the course of a single year they may be expected to deal with the work of a number of individual scientists, the invention and improvement of scientific instruments and the advances which these made possible, the existing standards of technology and at least something of the social life and beliefs of the age which is under discussion. And all this with adults who have, usually, very little scientific background and who are very much concerned with the present.

It is not surprising, therefore, that the number of tutors available to undertake this exacting type of work is extremely small. On the other hand there is scope for the tutor who can meet these demands. The interest which is known to exist among adults is a challenge to all, historians or scientists, capable of undertaking the work, and to those institutions concerned with the training of scientists with specialist qualifications in the history of science. 